\title{
Isolation of Mycoplasma spp. and serological responses in bulls prior to and following their introduction into Mycoplasma bovis-infected dairy herds
}

\author{
M. S. Hazelton, ${ }^{* 1}$ J. M. Morton,† K. L. Bosward,, P. A. Sheehy, ${ }^{\star}$ A. M. Parker, ${ }^{*}$ C. J. Dwyer,ł P. G. Niven,§ \\ and J. K. House* \\ ${ }^{*}$ Faculty of Science, Sydney School of Veterinary Science, The University of Sydney, Camden, New South Wales 2570, Australia \\ †Jemora Pty Ltd., Geelong, Victoria 3220, Australia \\ $\ddagger$ Smithton Veterinary Service, Tasmania 7330, Australia \\ §Pure Source Dairy Farm Company Ltd., Qihe County, Dezhou City, Shandong Province 251100, China
}

\begin{abstract}
With the common use of bulls for breeding following a period of artificial insemination in seasonally bred dairy herds, it is important to consider the potential role of the bull in transmission of Mycoplasma spp. within and between herds. This study aimed to assess the prevalence of Mycoplasma spp. in a population of bulls before and after use in Mycoplasma bovis-infected herds. The frequency of subclinical infection was also measured serologically postbreeding, and the association of Mycoplasma spp. on semen quality was evaluated. Mycoplasma bovis was isolated from 4 of 118 bulls after use in 4 herds infected with $M$. bovis. In the bulls, M. bovis seroprevalence increased from $9 \%$ prebreeding to $46 \%$ postbreeding with a total seroconversion rate of $44 \%$ across the 4 herds, with no evidence of clinical disease. There was no association of Mycoplasma spp. in the bulls' semen and abnormal palpation characteristics (enlarged or nodular) of seminal vesicular glands or poor semen quality attributes such as semen mass activity, sperm motility, and morphology. These results demonstrate a high degree of subclinical exposure of the bulls to $M$. bovis in infected herds and highlight the potential for bulls to be mycoplasma carriers within and between herds. Herd biosecurity protocols and control programs should take into account the potential role of bulls in the introduction and spread of Mycoplasma spp.
\end{abstract}

Key words: bull, dairy cattle, mycoplasma, semen

\section{INTRODUCTION}

Disease caused by Mycoplasma bovis and other $M y$ coplasma species within Australian dairy herds has become more common over the last 15 yr. Mycoplasmo-

Received January 16, 2018.

Accepted April 7, 2018.

${ }^{1}$ Corresponding author: mark.hazelton@sydney.edu.au sis can severely compromise the health and welfare of dairy cattle, and the financial impact on affected herds can be significant (Maunsell et al., 2011). Although the current incidence of outbreaks in Australia is modest, cases of clinical disease can be costly, largely because clinically affected animals are often culled to control the disease. To prevent the spread of infection within and between dairy herds, it is important that biosecurity protocols consider all classes of cattle, including bulls, when assessing the risk of pathogen introduction.

Mycoplasma spp. have been isolated from the genital tract and semen of bulls in several European countries, Canada, the United States, and the United Kingdom (Doig, 1981; Blom et al., 1983; Ball et al., 1987). However, Mycoplasma bovis has been isolated infrequently from bull semen (Ungureanu et al., 1986; Marciszewska and Zgorniak-Nowolielska, 1987; Parker et al., 2017b). The potential for bulls to act as carriers is of concern because of their potential to transmit $M$. bovis between and within herds. Recent genomic studies have confirmed this potential risk with the same strain of $M$. bovis isolated from a bull's prepuce and milk collected from mastitic quarters of dairy cows in the same region (Parker et al., 2016).

The pathogenicity of the Mycoplasma species most commonly isolated from bulls, Mycoplasma bovigenitalium, is less clear. Mycoplasma bovigenitalium has been isolated from infertile cattle, and seroreactions to $M$. bovigenitalium antigen have been reported to be more prevalent among infertile cattle (Tourtellotte, 1976; Catania et al., 2014). Although Mycoplasma bovigenitalium has also been isolated from bulls with naturally occurring seminal vesiculitis (Blom and Erno, 1967; Erno and Blom, 1972; al-Aubaidi et al., 1972), there is little evidence of disease in bulls in artificial breeding centers from which $M$. bovigenitalium was isolated from their prepuce and semen (Doig, 1981).

From a biosecurity and disease management perspective, it would be desirable to know the infective dynamics of mycoplasma in bulls. Pathogen detection 
via culture or application of molecular-based assays provides one option for monitoring the dynamics of infection in individual animals or populations. Several potential limitations to this approach include limits of detection and intermittent shedding. An alternative option is to monitor the pathogen-specific host immune response. A Mycoplasma bovis ELISA kit (BIO K 302, Bio-X Diagnostics, Rochefort, Belgium) for the detection of bovine antibody responses to $M$. bovis antigen in blood and milk is commercially available. This ELISA has been commonly used for evaluating herd infection status using bulk tank milk (Arede et al., 2016; Parker et al., 2017a).

Mycoplasmas colonize mucosal surfaces of the nose, eye, middle ear, vagina, mammary gland (Ruhnke, 1994; Pfützner and Sachse, 1996; Maunsell et al., 2011), and prepuce (Doig, 1981). Transmission between animals can occur via aerosolization of nasal secretions (Fox, 2012); ingestion of contaminated colostrum or milk (Maunsell et al., 2012); contamination of milker's hands, milking equipment, or intramammary treatments (Fox et al., 2005); and transfer of contaminated semen and uterine secretions (Doig, 1981).

The transfer of bulls between herds represents a biosecurity risk. Although clinical disease is rarely reported in bulls, they are potential contributors to transmission of mycoplasmas within herds. In addition, assessment of effects of mycoplasma on bull fertility is needed. In Australian seasonal and split-calving dairy herds, all breeding takes place only within restricted time periods, commonly of 6 to $15 \mathrm{wk}$ duration. Following an initial period of AI, bulls are commonly run with the lactating herd for the remainder of the breeding period. Thus, bulls play a key role in maximizing the proportion of the herd that is pregnant at the end of the breeding period. The objectives of this study were (1) to assess the frequency of $M$. bovis infections and serological responses in bulls following exposure to $M$. bovis-infected herds, (2) to evaluate the prevalence of Mycoplasma spp. in the semen and prepuce of bulls before and following introduction into $M$. bovis-infected dairy herds, and (3) to assess associations between Mycoplasma spp. in semen and sperm motility, sperm morphology, and abnormalities of seminal vesicular glands.

\section{MATERIALS AND METHODS}

\section{Study Overview}

Five dairy herds either recently or currently experiencing clinical disease in milking cows associated with $M$. bovis were enrolled in the study, which was conducted between July and September 2013. Each of the herds used bulls drawn from a common pool. Three herds practiced autumn-only calvings (seasonal) and 2 herds practiced autumn and spring calvings (split calving). Within any particular year, all AI and natural services occurred within 1 or 2 restricted breeding periods, respectively. In each breeding period, a period of AI was followed by introduction of bulls with the lactating herd for the remainder of the breeding period (the bull breeding period). Prior to the bulls running with the lactating cows in the bull breeding period, the infection status of the milking cows within each herd was described according to clinical disease history and serological results from a cohort of milking cows. The mycoplasma infection status of the bulls was assessed prebreeding using culture and PCR. The serological status of each bull was evaluated before and after the herd's bull breeding period, and the mycoplasma infection status of each bull was reassessed postbreeding. Palpation characteristics of the bulls' seminal vesicles were assessed prebreeding, and semen quality was evaluated pre- and postbreeding in relation to mycoplasma infection status. The study had the approval of the University of Sydney Animal Ethics Committee (protocol number 2013/6046).

\section{Bulls}

All bulls were managed in a central facility isolated from the study herds. Prebreeding bull breeding soundness examinations were performed over a $3-\mathrm{d}$ period between a maximum of -35 and $-30 \mathrm{~d}$ and minimum of -33 and $-28 \mathrm{~d}$ before the bull breeding period start dates (d 0) for their herds. (Bull breeding period start dates varied by $5 \mathrm{~d}$ between herds.) Of the bulls that passed their examination, a total of 150 were allocated by the bull herd manager to the 5 study herds and enrolled into the study. Of the bulls enrolled, $70 \%(\mathrm{n}=$ 105) were virgin, aged between 2 and $2.5 \mathrm{yr}$, with the remaining $30 \%(\mathrm{n}=45)$ being mature nonvirgin bulls. All were Holstein-Friesian. Data collected as part of the prebreeding soundness examination were used for this study including semen mass activity, semen progressive motility, and results of assessments of seminal vesicular glands for abnormalities (enlarged and nodular) via rectal palpation. Once the 150 study bulls were enrolled into the study, fresh semen and blood were collected from each bull over the 2 consecutive days immediately following the prebreeding soundness examinations. Electro-ejaculation was used to collect a fresh semen sample from each bull into a sterile $15-\mathrm{mL}$ polypropylene tube (Biologix, Shandong, China). Two drops of fresh semen were preserved in buffered formalin to evaluate the percentage of normal sperm. A smear and 
Romanowsky stain (Rapid Diff No. 1 and 2, Australian Biostain P/L, VIC, Australia) of each fresh semen sample was prepared for leukocyte analysis. Blood was collected from the tail vein into a $10-\mathrm{mL}$ SSST II Advanced Vacutainer Tube (BD, Franklin Lakes, NJ). Once collected, fresh semen samples (for mycoplasma culture) and blood (for serology) were refrigerated and transported on ice until they reached the laboratory within 2 to $3 \mathrm{~d}$.

Bulls were allocated to the 5 herds at a ratio of approximately 1 bull per 30 cows with a consistent ratio of virgin to nonvirgin bulls selected for each herd. The 150 study bulls were the only bulls used in the study herds. The bull breeding period durations varied between herds from 12 to $17 \mathrm{~d}$, preceded in each herd by approximately 8 wk of breeding using AI. Accurate clinical mycoplasma-related disease data could not be obtained from one of the study herds, so the 27 study bulls allocated to this herd were excluded from the postbreeding assessments. Cow serology results for this herd were also excluded. The bulls from this herd displayed similar serological and semen culture results to the remaining 4 study herds. A further 4 of the 150 bulls were diverted to nonstudy herds, and one bull allocated to a study herd died soon after the end of the breeding period of unknown cause before postbreeding samplings were performed. Therefore, 150 bulls were evaluated prebreeding and the 118 living bulls that had been allocated to the 4 retained study herds were evaluated postbreeding. In total, of these 118 bulls, 27, 32,30 , and 29 were used within herds $1,2,3$, and 4 , respectively, and they were resampled 12 or $13 \mathrm{~d}$ after the end of the bull breeding periods; 55 to $57 \mathrm{~d}$ after their prebreeding samples were collected. The ends of the bull breeding period were on the same calendar date for each herd. Postbreeding sampling was also conducted over 2 consecutive days for all bulls, between 24 and 30 $\mathrm{d}$ after the bulls' breeding period start dates in their respective herds. The same prebreeding sampling protocol and semen assessments were used postbreeding, except the seminal vesicular glands of each bull were not re-examined. Additionally, because the prepuce is the most likely site of mycoplasma contamination of semen (Fish et al., 1985) and in an attempt to increase sensitivity of Mycoplasma spp. detection, preputial swabs were collected from all 118 bulls postbreeding by rubbing a rayon tip swab along the prepuce of the erect penis at the time of fresh semen collection. Each swab was placed directly into a tube containing Amies transport medium (FL Medical, Torreglia, Italy) and refrigerated before transport to the laboratory within 2 to 3 d. Any penile lesions (ulcerations, erosions, nodules, or trauma wounds) were noted at collection of the postbreeding samples.

\section{Herd Details and Cows}

Of the 4 retained study herds, 3 calved seasonally (in autumn) and the 4th herd used split calving, with calving periods in both autumn and spring. Herd records (date of culling, death, or euthanasia) and PCR diagnostic test results for milk, joint fine needle aspirate, or swab samples (date of diagnosis) were collated back to the first $M$. bovis case in each herd and used to describe the timing and number of clinical cases in relation to the start of the bull breeding period (d 0). Some clinical cases attributed to $M$. bovis in the herd records were based on clinical signs consistent with previously diagnosed $M$. bovis cases. The time of $M$. bovis clinical cases was categorized by day (before d $-150,-150$ to -101 , -100 to $-51,-50$ to -1 , or 0 up to +17 d) relative to the start of the bull breeding period $(\mathrm{d} 0)$. The end of the clinical case monitoring period was defined as the end of the bull breeding period for each herd. Milking herd size of each herd at the time of prebreeding sampling of the cows was recorded. From each herd, blood was collected from 50 cows selected systematically (e.g., approximately every 10th cow from a herd of 500) from the rotary platform during a milking session $4 \mathrm{wk}$ before the bull breeding period to evaluate the serological $M$. bovis profile of each herd. The sample size of 50 cows was chosen for both statistical and practical reasons, allowing reasonable precision but also being acceptable to herd managers and staff. At an observed seroprevalence of $20 \%$, precision (assessed as half of the exact mid-P 95\% CI) was approximately $\pm 10 \%$.

\section{Sample and Laboratory Analyses}

Mycoplasma Species Isolation and Identification. The fresh semen samples and preputial swabs were cultured on Mycoplasma agar [Mycoplasma agar base (Oxoid CM0401, Waltham, MA); Milli-Q water; $0.2 \% \mathrm{wt} / \mathrm{vol}$ calf thymus DNA (Sigma D1501, Sigma, St. Louis, MO); Mycoplasma Selective Supplement G (Oxoid SR0059C); prepared by Elizabeth Macarthur Agricultural Institute, NSW Department of Primary Industries, NSW, Australia]. Agar plates were incubated at $37^{\circ} \mathrm{C}$ in candle jars to achieve elevated $\mathrm{CO}_{2}$ levels for 5 to $10 \mathrm{~d}$. Following incubation, the plates were examined for colonies with gross morphology consistent with Mycoplasma spp. For each culture, several colonies were selected and aseptically transferred into $40 \mu \mathrm{L}$ of sterile PBS. The PBS suspension was vortexed, with $10 \mu \mathrm{L}$ sub-cultured onto mycoplasma agar and $5 \mu \mathrm{L}$ used in each PCR reaction. Colonies from the subculture plates were subsequently harvested and stored in Cryobead tubes (Protect Multipurpose, Thermo Fisher Scientific, Waltham, MA) at $-80^{\circ} \mathrm{C}$. 
$\boldsymbol{P C R}$. Several PCR assays were used to determine the identity of the culture isolates. First, isolates were processed using a Mycoplasma spp. conventional PCR as described by Parker et al. (2017b). This was followed by an Acholeplasma laidlawii conventional PCR assay designed using the Primer3 software program (Untergasser et al., 2012; Table 1). For each PCR assay, reaction mixtures contained $0.25 \mathrm{~m} M$ deoxynucleotide triphosphates, $2.5 \mathrm{mM} \mathrm{MgCl}_{2}, 1.5 \mathrm{U}$ of GoTaq, $0.25 \mu M$ of each primer, $8 \mu \mathrm{L}$ of $5 \times$ buffer, and $5 \mu \mathrm{L}$ of PBS cell suspension in a final volume of $40 \mu \mathrm{L}$. Cycling conditions were $94^{\circ} \mathrm{C}$ for $5 \mathrm{~min}$, followed by 35 cycles of $94^{\circ} \mathrm{C}$ for $30 \mathrm{~s}, 55^{\circ} \mathrm{C}$ for $30 \mathrm{~s}, 72^{\circ} \mathrm{C}$ for $1 \mathrm{~min}$, and a final extension of $72^{\circ} \mathrm{C}$ for $5 \mathrm{~min}$. The assay was performed on a Bio-Rad-T100 Thermocycler (Bio-Rad Laboratories Pty Ltd., Gladesville, NSW, Australia). All PCR products amplified by the PCR assays underwent Sanger Sequencing at the Australian Genome Research Facility Ltd. (Westmead, NSW, Australia) to validate species identification. Isolates that failed to amplify using the universal Mycoplasma spp. or A. laidlawii PCR assays were evaluated with a species specific real-time-probebased multiplex PCR assay as described by Parker et al. (2017b), targeting M. bovis, M. bovigenitalium, and Mycoplasma californicum. Reaction mixtures contained $0.5 \mathrm{~m} M$ deoxynucleotide triphosphates, $5 \mathrm{mM} \mathrm{MgCl}_{2}$, $0.5 \mathrm{U}$ of GoTaq polymerase, $1 \mu M$ each primer, 0.25 $\mu M$ probe, $2.0 \mu \mathrm{L}$ of $5 \times$ buffer, and $2 \mu \mathrm{L}$ of PBS cell suspension in a final volume of $10 \mu \mathrm{L}$. Cycling conditions were $95^{\circ} \mathrm{C}$ for $60 \mathrm{~s}$, followed by 40 cycles of $95^{\circ} \mathrm{C}$ for $30 \mathrm{~s}, 60^{\circ} \mathrm{C}$ for $30 \mathrm{~s}$, and $72^{\circ} \mathrm{C}$ for $30 \mathrm{~s}$. The assay was performed on a RotorGene 3000 RT-PCR System Thermocycler (Qiagen Pty Ltd., Chadstone Centre, VIC, Australia).

Serology. Sera were stored at $-80^{\circ} \mathrm{C}$ before serological evaluation using a commercially available $\mathrm{Myco-}$ plasma bovis ELISA kit (BIO K 302, Bio-X Diagnostics, Rochefort, Belgium). The ELISA uses a recombinant protein from $M$. bovis expressed by Escherichia coli as a plate antigen. The assay was performed according to the manufacturer's instructions. Briefly, $10 \mu \mathrm{L}$ of sera was diluted 1/100 using supplied dilution buffer before being added to individual wells with each sample analyzed in duplicate. Positive and negative control sera were run in triplicate. Two wells remained blank for the correction of background. Following incubation at $21^{\circ} \mathrm{C}$ for $1 \mathrm{~h}$, the plate was washed with the supplied washing solution. Conjugate solution (anti-mammalian IgG peroxidase, protein $\mathrm{G}$ horseradish peroxidase-labeled) was diluted 1:50 using the supplied dilution buffer and $100 \mu \mathrm{L}$ was then added to each well and incubated for $1 \mathrm{~h}$ at $21^{\circ} \mathrm{C}$. Following plate washing, $100 \mu \mathrm{L}$ of the supplied chromogen solution (tetramethylbenzidine) was added to each well before incubation for $10 \mathrm{~min}$ at $21^{\circ} \mathrm{C}$. The reaction was subsequently stopped using $50 \mu \mathrm{L}$ of the supplied stop solution (1 $M$ phosphoric acid) and the absorbance optical density (OD) of each well was read using a Polarstar Optima (450 nm) microplate reader (POLARstar Optima, BMG Labtech, Ortenberg, Germany). Sample OD was adjusted by subtracting the average OD from the blank wells. Each microplate was validated using the specified OD threshold for the positive and negative control sera. Optical density coefficient (ODC\%) was calculated as the proportion of the average positive control OD and was calculated for each sample according to the formula: (OD sample - OD negative serum)/(OD positive serum - OD negative serum) $\times 100$. Standard deviation and coefficient of variation was calculated for each sample pair duplicate. Duplicate samples with a coefficient of variation greater than 0.2 and $\mathrm{ODC} \%$ greater than 20 were rejected and the assay repeated. According to the manufacturer's directions, sera with an ODC\% equal to or greater than $37 \%$ were considered positive. An ODC\% less than 37\% was considered negative.

Semen and Sperm Quality. Semen mass activity and progressive motility were assessed crush-side according to the guidelines for the Australian Cattle Veterinarians Bull Breeding Soundness Examination (Beggs et al., 2013). Semen mass activity is a function of both sperm concentration and the proportion of sperm that are progressively motile. Semen mass activity was assessed based on the wave/swirl motion and gross motility of the semen on a warmed slide $\left(37^{\circ} \mathrm{C}\right)$ under $100 \times$ magnification. Semen mass activity was scored on a scale from 0 to 5 where 0 indicated no swirl motion and 5 indicated a fast distinct swirl with continuous dark waves (the latter being consistent with high sperm concentration and a high proportion of sperm that are progressively motile). Semen progressive

Table 1. Primers used for the Acholeplasma laidlawii conventional PCR and culture speciation

\begin{tabular}{lll}
\hline Name $^{1}$ & Sequence & Target \\
\hline AlaiF & 5'-AACAAAGGGCACACAGTGGA-3' $^{\prime}$ & $\begin{array}{l}\text { 16S-23S rRNA intergenic spacer region gene of } \text { A. laidlawii (GenBank accession } \\
\text { no. AY740437) }\end{array}$ \\
AlaiR & $5^{\prime}$-CAGGGCTCTCACCTTCTTCG-3' &
\end{tabular}


motility estimated the proportion of sperm that were moving rapidly in a forward direction through their own propulsion after dilution with a drop of warmed $0.9 \%$ saline solution on a warmed slide $\left(37^{\circ} \mathrm{C}\right)$ under $400 \times$ magnification; each semen sample was categorized as having $<30 \%, 30-50 \%$, or $>50 \%$ of sperm that were progressively motile.

For all pre- and postbreeding fresh semen samples, a sub-sample was preserved in buffered formalin. From all bulls with $M$. bovigenitalium, A. laidlawii, and no growth on culture of fresh semen, random numbers generated by Microsoft Excel (2010, Microsoft Corp., Redmond, WA) were used to select 15 bulls from each category to have sperm morphological analysis performed on their corresponding preserved sub-sample, disregarding whether they were pre- or postbreeding samples. Sperm morphology was also analyzed in all semen samples from which M. bovis $(\mathrm{n}=4)$ and Mycoplasma canadense ( $\mathrm{n}$ $=1$ ) was isolated. The percentages of sperm that were morphologically normal were assessed according to the procedure outlined in Salamon's Artificial Insemination of Sheep and Goats (Evans and Maxwell, 1987). The corresponding Romanowsky-stained semen smears of these 50 samples were analyzed for the presence of leukocytes. The neutrophil and lymphocyte counts were categorized by averaging the number of each cell type counted per high-power field (hpf; $400 \times$ ) over 10 fields of view; $0=$ no cells observed, $+=<5$ cells per hpf, $++=5-10$ cells per hpf, $+++=>10-15$ cells per hpf, and $++++=>15$ cells per hpf.

\section{Statistical Analyses}

All $P$-values were 2 -sided. Prevalences were compared between 2 groups using Fisher's exact test, calculated using the csi command in Stata (versions 14 and 15, StataCorp, College Station, TX). No clustering was assumed for prebreeding prevalences. For the one comparison of postbreeding prevalences, any clustering of bull by the herd that the bull had been used in was disregarded. Agreement between semen Mollicutes results was assessed using kappa for nonordered categories, calculated using the Pairs etc module (version 3.59) of WinPepi (version 11.64; Abramson, 2011).

The association between semen Mollicutes status (none isolated, M. bovigenitalium, or A. laidlawii) and enlargement of seminal vesicular glands in the bulls on rectal palpation at prebreeding examination was assessed with exact logistic regression with adjustment for bull age $(2,3-6$, or $>6$ yr) using Stata's exlogistic command. Conditional scores tests and mid $P$-values were used. The association with nodularity of the seminal vesicular glands was assessed in the same way.
Separately within each of prebreeding and postbreeding samples, semen mass activity was compared by semen Mollicutes status (none isolated, M. bovigenitalium, M. bovis, or A. laidlawii) with the Kruskall-Wallis test with the chi-squared statistic adjusted for ties, using Stata's kwallis command. Semen progressive motility postbreeding was assessed in the same way disregarding any clustering of bull within herd. Because each semen progressive motility result prebreeding was either $30-50 \%$ or $>50 \%$, the association between semen Mollicutes status and semen progressive motility was instead assessed with exact logistic regression using Stata's exlogistic command. Conditional score tests and mid $P$-values were used. For analyses of seminal vesicular gland abnormalities, semen mass activity, and semen progressive motility, the unspeciated culture positive and $M$. canadense bulls were excluded from analyses because only 1 bull had each result, these were not recorded for 1 bull, and 5 out of the 150 bulls were excluded due to ambiguous bull identification numbers recorded at the prebreeding soundness examinations.

Means for percentages of sperm that had normal appearance were compared by semen Mollicutes status using linear regression with bull fitted as a random effect. Stata's xtreg command was used with maximum likelihood estimation. Of the 50 samples assessed, 48 were used. One $M$. bovis sample was azospermic and the $M$. canadense sample was excluded because only 1 sample had this Mycoplasma species.

Proportions of samples with neutrophils were compared by semen Mollicutes status with logistic regression with a random effect of bull, fitted using Stata's xtlogit command. Proportions of samples with lymphocytes were compared in the same way. Of the 50 semen samples assessed for neutrophils and lymphocytes, some of the results had to be excluded for the following reasons: 1 of the semen smears made from an $M$. bovis bull had blood contamination with no spermatozoa present; all 3 other M. bovis samples that had neutrophils were excluded because the exposure category, M. bovis, predicted presence of neutrophils perfectly so that category could not be fitted in the maximum likelihood logistic regression model; another semen smear from a bull with no culture growth from semen had no material on the slide for examination for neutrophils and lymphocytes; and there was a single $M$. canadense semen smear so this category also could not be fitted in the logistic regression model. Thus, 44 and 47 samples were used for the analyses of neutrophils and lymphocytes, respectively. Proportions of samples with neutrophils were also compared between $M$. bovis and no growth samples using Fisher's exact test, calculated using the csi command in Stata, disregarding 
Table 2. Herd size, number of clinical Mycoplasma bovis cases in the dry cows and milking herd, and timing of diagnosis, culling or death/ euthanasia of these cases by category in relation to the start of the bull breeding period $(\mathrm{d} 0)$

\begin{tabular}{lccccrr}
\hline & & & \multicolumn{3}{c}{ Time of $M$. bovis cases (d) } \\
\cline { 4 - 7 } Herd & $\begin{array}{c}\text { Milking } \\
\text { herd size }\end{array}$ & $\begin{array}{c}\text { Total no. of } \\
\text { M. bovis cases }\end{array}$ & Before -150 & -150 to -101 & -100 to -51 & -50 to -1 \\
\hline 1 & 880 & 83 & $23^{3}$ & 4 & 52 & 4 \\
2 & 932 & 73 & 0 & 0 & 50 & 13 \\
3 & 963 & 33 & 0 & 3 & 27 & 3 \\
4 & 920 & 80 & 0 & 0 & 39 & 10 \\
\hline
\end{tabular}

${ }^{1}$ No. of cows in milking herd at prebreeding cow sampling date.

${ }^{2}$ Contains the bull breeding period for the first 12 to $17 \mathrm{~d}$, variable by herd. End of clinical case monitoring period was d $16,15,17$, and 12 for herds $1,2,3$, and 4 , respectively.

${ }^{3}$ All clinical cases diagnosed during the milking season before that of the study sampling period.

clustering of sample within bull. The 17 samples used for this analysis were from 16 bulls.

Seroprevalences and mean ODC\% were compared between pre- and postbreeding using generalized estimating equations models fitted with Stata's xtgee command. The individual bull was the panel variable; robust (Huber/White/sandwich estimators) of variance and exchangeable correlation structures were used. For seroprevalences, the binomial distribution and logit link were used, whereas for mean ODC\%, the Gaussian distribution and log link were used. Exponentiated coefficients from these models were interpreted as odds ratios and ratios of arithmetic means, respectively. Joint terms for interactions between time (pre- or postbreeding) and herd were assessed using Wald tests. Risk of seroconversion was compared by herd with logistic regression using Stata's logistic command.

\section{RESULTS}

\section{Description of Herd Mycoplasma Clinical Patterns}

The start of the bull breeding period for each herd was designated $\mathrm{d} 0$. The number of $M$. bovis cases in each herd and timing of their diagnosis in relation to d 0 are reported in Table 2. The monitoring period for clinical cases ended on the final day of the bull breeding period for each herd, which was d 16, 15, 17, and 12 for herds $1,2,3$, and 4 , respectively.

Herd 1. The first of 23 clinical $M$. bovis cases was identified at $\mathrm{d}-308$, during lactations that commenced before the study period. A further 60 cases were identified at the beginning of the next calving period, starting with arthritis/tenosynovitis in the dry cows and continuing with cases of mastitis in the milking cows through to $\mathrm{d}-17$. Of the $83 \mathrm{M}$. bovis cases, 52 were confirmed with PCR and the remaining 31 had consistent clinical signs with previously diagnosed cases.
Herd 2. The first clinical cases presented with $M$. bovis mastitis at d -95 . A total of 73 cases (59 confirmed with PCR; 14 with consistent clinical signs) were identified through to d 11.

Herd 3. The first clinical $M$. bovis mastitis case was diagnosed at $d-112$. A total of 33 cases (24 confirmed with PCR; 9 with consistent clinical signs) were identified up to $\mathrm{d}-22$.

Herd 4. The first clinical cases of $M$. bovis mastitis were diagnosed at $\mathrm{d}-81$. A total of $80 \mathrm{M}$. bovis cases (69 confirmed with PCR; 11 with consistent clinical signs) were identified through to d 12 .

Mastitis was the most common disease presentation for all herds. At least 19, 4, and 6 cases of arthritis/ tenosynovitis cases were present in herd 1,2 and 3, respectively, either in addition or alternatively to mastitis.

\section{Serology of Cows}

Prebreeding cow samplings were performed on $\mathrm{d}-30$, $-31,-29$, and -33 for herds $1,2,3$, and 4, respectively. Prebreeding $M$. bovis seroprevalences and mean ODC\% of the cows from each herd are presented in Table 3. Note that the herd with the longest history of clinical disease (herd 1) had the lowest cow seroprevalence and mean ODC\%, whereas the herd with the most recent

Table 3. Prebreeding Mycoplasma bovis seroprevalence and mean optical density coefficient (ODC\%) ${ }^{1}$ of 50 cows from each herd

\begin{tabular}{lcc}
\hline Herd & Seroprevalence $(\%)$ & Mean ODC\% \\
\hline 1 & 14.0 & 21.9 \\
2 & 24.0 & 25.6 \\
3 & 32.0 & 35.1 \\
4 & 72.0 & 63.7 \\
\hline
\end{tabular}

${ }^{1}$ Calculated as the proportion of the average positive control optical density. 
history of clinical disease (herd 4) had the highest cow seroprevalence and mean ODC\%.

\section{Bulls}

Mycoplasma Species Isolation. Five species within the Mollicutes class were isolated from the bulls: M. bovigenitalium, M. bovis, M. canadense, Mycoplasma sp. Zaradi2, and A. laidlawii. The distribution of these isolates from the bulls collected pre- and postbreeding and their isolation site are presented in Table 4. Within each of pre- and postbreeding samplings, no bull had more than one species identified from the same site. Mycoplasma bovis was not isolated from any of the 150 bulls prebreeding. Apparent prevalences of M. bovigenitalium and A. laidlawii in fresh semen prebreeding were $26 \%(\mathrm{n}=39 / 150)$ and $25.3 \%(\mathrm{n}=38 / 150)$, respectively (Table 4). Prevalences did not differ significantly between virgin and nonvirgin bulls. Mycoplasma bovigenitalium was isolated from $28 \%(\mathrm{n}=29 / 105)$ of the virgin bulls and $22 \%(\mathrm{n}=10 / 45)$ of the nonvirgin bulls prebreeding $(P=0.547)$. Acholeplasma laidlawii was isolated from $28 \%(\mathrm{n}=29 / 105)$ of the virgin bulls and $20 \%(\mathrm{n}=9 / 45)$ of the nonvirgin bulls prebreeding $(P$ $=0.414)$.

Of the 118 bulls included in the postbreeding analysis, apparent prevalences for detection from at least one site for $M$. bovigenitalium, $M$. bovis, and A. laidlawii were $41 \%(\mathrm{n}=48 / 118), 3 \%(\mathrm{n}=4 / 118)$, and $19 \%(\mathrm{n}=$ $22 / 118$ ), respectively (Table 4 ). The 4 bulls with $M$. bovis were from herd $2(\mathrm{n}=1)$, herd $3(\mathrm{n}=2)$, and herd 4 $(\mathrm{n}=1)$. Mycoplasma bovis was isolated from 2 of the 81 bulls with a prebreeding virgin sexual history and 2 of the 37 bulls with a prebreeding nonvirgin sexual history. Interestingly, of the 4 bulls with $M$. bovis in their semen postbreeding, $2(50 \%)$ had penile lesions compared with $5(9 \%)$ of the 54 bulls with no culture growth from their semen postbreeding $(P=0.067)$. The use of preputial swabs in addition to culture and PCR of fresh semen slightly increased the detection of $M$. bovigenitalium (by $1.7 \%$ from $39.0 \%$ or $46 / 118$ to $40.7 \%$ or $48 / 118$ ), and A. laidlawii (by $7.6 \%$ from $11.0 \%$ or $13 / 118$ to $18.6 \%$ or 22/118; Table 4). Species isolated from each bull's fresh semen pre- and postbreeding are shown in Table 5. No agreement between pre- and postbreeding semen results was above that expected by chance. Of the 118 bulls sampled pre- and postbreeding, disregarding the 1 bull with an unspeciated isolate prebreeding and the 1 bull with $M$. canadense postbreeding, kappa was -0.01 (95\% CI -0.13 to 0.11). A kappa of 1 indicates perfect agreement, and a kappa of 0 indicates no agreement above that expected by chance.

Seminal Vesicular Glands. Seminal vesicular glands were assessed by rectal palpation only at the

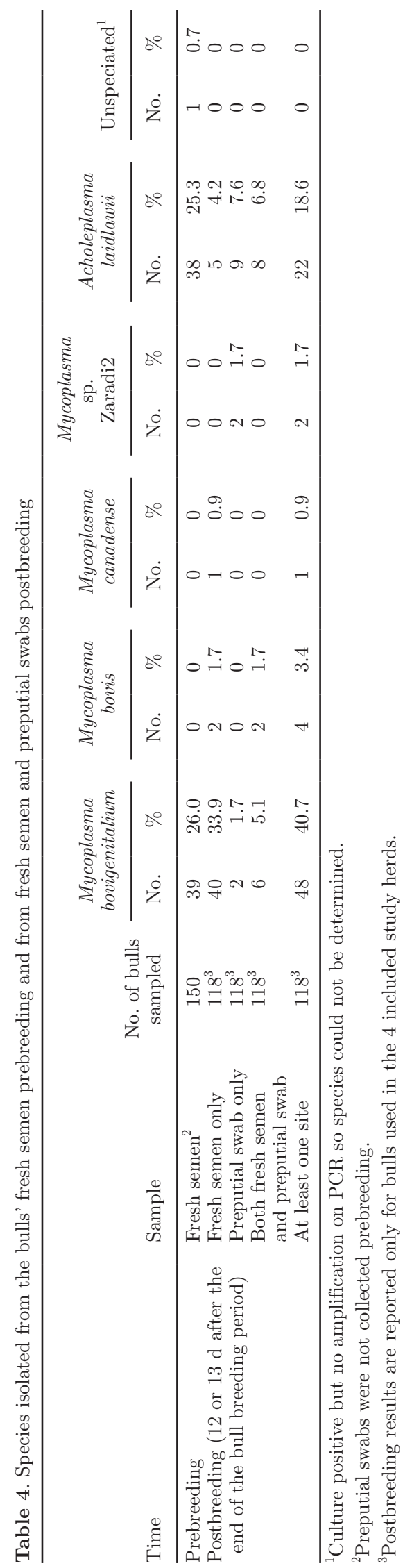


MYCOPLASMA IN DAIRY BULLS

Table 5. Comparison of species isolated from each bull's pre- and postbreeding fresh semen ${ }^{1}$

\begin{tabular}{lccccc}
\hline & \multicolumn{4}{c}{ Postbreeding species } \\
\cline { 2 - 6 } Prebreeding species & $\begin{array}{c}\text { No } \\
\text { growth }\end{array}$ & $\begin{array}{c}\text { Acholeplasma } \\
\text { laidlawii }\end{array}$ & $\begin{array}{c}\text { Mycoplasma } \\
\text { bovigenitalium }\end{array}$ & $\begin{array}{c}\text { Mycoplasma } \\
\text { bovis }\end{array}$ & $\begin{array}{c}\text { Mycoplasma } \\
\text { canadense }\end{array}$ \\
\hline No growth & 22 & 7 & 21 & 3 & 0 \\
A. laidlawi & 20 & 2 & 10 & 0 & 1 \\
M. bovigenitalium & 11 & 4 & 15 & 0 & 0 \\
Unspeciated $^{2}$ & 1 & 0 & 0 & 33 & 0 \\
Total & 54 & 13 & 46 & 4 & 1 \\
\hline
\end{tabular}

${ }^{1}$ This table does not include culture-positive results from preputial swabs.

${ }^{2}$ Culture positive but no amplification on PCR, so species could not be determined.

prebreeding soundness examinations. No significant association was observed between semen Mollicutes status (none isolated, $M$. bovigenitalium, or A. laidlawii) and either enlarged (overall $P$ adjusted for bull age $=$ 0.248 ) or nodular (overall $P$ adjusted for bull age $=$ 0.800 ) seminal vesicular glands in the bulls. Percentages of bulls with enlarged seminal vesicular glands by semen Mollicutes status were as follows: none isolated $13 \%$ ( $\mathrm{n}=9 / 69) ;$ M. bovigenitalium 26\% ( $\mathrm{n}=10 / 39)$; A. laidlawii $23 \%(\mathrm{n}=8 / 35)$; and unspeciated isolate $0 / 1$. Percentages of bulls with nodular seminal vesicular glands by semen Mollicutes status were as follows: none isolated 10\% ( $\mathrm{n}=7 / 69), M$. bovigenitalium 13\% ( $\mathrm{n}=$ 5/39), A. laidlawii $11 \%(\mathrm{n}=4 / 35)$, and unspeciated isolate $0 / 1$.

Semen and Sperm Analyses. Neither semen mass activity nor semen progressive motility varied significantly with semen Mollicutes status (none isolated, $M$. bovigenitalium, $M$. bovis, or A. laidlawii) in the semen collected prebreeding (overall $P=0.254$ and $P=0.622$, respectively) and postbreeding (overall $P=0.189$ and $P=0.930$, respectively). For semen with no growth, $M$. bovigenitalium and A. laidlawii, percentages of samples with semen mass activity $\geq 3.5$ were, respectively, 32 , 49 , and $31 \%$ prebreeding and 43,57 , and $46 \%$ postbreeding. Of the 4 samples with $M$. bovis postbreeding, 1 had semen mass activity $\geq 3.5$. For semen with no growth, M. bovigenitalium, and A. laidlawii, percentages of samples with semen progressive motility $>50 \%$ were, respectively, 93, 95, and 97\% prebreeding and 65,70 , and $69 \%$ postbreeding. Of the 4 samples with $M$. bovis postbreeding, 2 had semen progressive motility $>50 \%$. Denominators were as for seminal vesicular glands, reported above.

The percentages of sperm that had normal appearance by Mollicutes status are summarized in Table 6 . No significant association was observed between semen Mollicutes status (none isolated, $M$. bovigenitalium, $M$. bovis, or A. laidlawii) and the percentage of sperm that had normal appearance (overall $P=0.504$ ).
Of the 20 semen samples with neutrophils, 19 were $+(<5$ cells per hpf $)$ and 1 was $++(5-10$ cells per hpf). Percentages of samples with neutrophils were A. laidlawii, $47 \%$ ( $\mathrm{n}=7 / 15) ;$ M. canadense, $100 \%$ ( $\mathrm{n}$ $=1 / 1) ; M$. bovigenitalium, $20 \%(\mathrm{n}=3 / 15) ;$ M. bovis, $100 \%(\mathrm{n}=3 / 3)$; and no growth, $43 \%(\mathrm{n}=6 / 14)$. No significant association was observed between semen Mollicutes status (none isolated, M. bovigenitalium, or A. laidlawii) and presence of neutrophils (overall $P=$ 0.281 ). The proportions with neutrophils also did not differ significantly between $M$. bovis bulls and bulls with no growth [neutrophils present for all $3 \mathrm{M}$. bovis bulls (100\%) compared with 6 out of $14(43 \%)$ for bulls with no growth; $P=0.206]$. Of the 15 semen samples with lymphocytes, 13 were $+(<5$ cells per hpf $)$ and 2 were $++++(>15$ cells per hpf $)$. Percentages of semen smears that had lymphocytes were similar for all semen Mollicutes statuses (27-33\%). Percentages of samples with lymphocytes were A. laidlawii, $33 \%(\mathrm{n}=5 / 15)$; M. canadense, $100 \%(\mathrm{n}=1 / 1) ;$ M. bovigenitalium, $27 \%$ $(\mathrm{n}=4 / 15) ; M$. bovis, $33 \%(\mathrm{n}=1 / 3)$; and no growth, $29 \%(\mathrm{n}=4 / 14)$. No significant association was present between semen Mollicutes status (none isolated, $M$. bovigenitalium, $M$. bovis, or A. laidlawii) and presence of lymphocytes (overall $P=0.980$ ).

Table 6. Percentages of sperm that had normal appearance in fresh semen of bulls by Mollicutes species isolated pre- or postbreeding

\begin{tabular}{lccc}
\hline & & \multicolumn{2}{c}{$\begin{array}{c}\text { \% of sperm that } \\
\text { had normal appearance }\end{array}$} \\
\cline { 3 - 5 } Species & $\begin{array}{c}\text { No. of } \\
\text { samples }\end{array}$ & Mean ${ }^{1}$ & Range \\
\hline Mycoplasma bovigenitalium & 15 & 94 & $88-98$ \\
Acholeplasma laidlawii & 15 & 95 & $91-98$ \\
Mycoplasma bovis & 4 & $92^{2}$ & $90-97^{2}$ \\
Mycoplasma canadense & 1 & 91 & 91 \\
None isolated & 15 & 94 & $78-98$ \\
\hline
\end{tabular}

${ }^{1}$ Overall $P$-value for differences between means $0.504 ; M$. canadense was excluded from that analysis.

${ }^{2}$ Mean and range for 3 samples. The 4 th sample was azospermic. 
Table 7. Prebreeding and postbreeding seroprevalences, means and SD of optical density coefficient (ODC\%), and seroconversion incidences of 118 bulls tested on both occasions, by herd

\begin{tabular}{|c|c|c|c|c|c|c|c|}
\hline \multirow[b]{2}{*}{ Herd } & \multirow[b]{2}{*}{$\begin{array}{l}\text { No. of bulls } \\
\text { sampled }\end{array}$} & \multicolumn{2}{|c|}{ Prebreeding } & \multicolumn{4}{|c|}{ Postbreeding } \\
\hline & & $\begin{array}{c}\text { Seroprevalence } \\
(\%)\end{array}$ & $\begin{array}{c}\text { Mean } \\
\text { ODC\% (SD) }\end{array}$ & $\begin{array}{c}\text { Seroprevalence } \\
(\%)\end{array}$ & $\begin{array}{c}\text { Mean } \\
\text { ODC\% (SD) }\end{array}$ & $\begin{array}{l}\text { No. of bulls that } \\
\text { were seronegative } \\
\text { prebreeding }\end{array}$ & $\begin{array}{l}\text { Seroconversion } \\
\text { incidence }^{1}(\%)\end{array}$ \\
\hline 1 & 27 & 7.4 & $18.0(11.7)$ & 25.9 & $30.1(34.6)$ & 25 & 28.0 \\
\hline 2 & 32 & 6.3 & $18.8(23.6)$ & 46.9 & $40.0(32.6)$ & 30 & 43.3 \\
\hline 3 & 30 & 10.0 & $20.2(24.8)$ & 40.0 & $43.5(49.6)$ & 27 & 40.7 \\
\hline
\end{tabular}

${ }^{1}$ Percentages of bulls seronegative prebreeding that were seropositive postbreeding; postbreeding samples were collected 55 to $57 \mathrm{~d}$ after the prebreeding sample was collected from the same bull.

Serology. Pre- and postbreeding M. bovis seroprevalences and mean ODC\% of the 118 bulls tested at both pre- and postbreeding are presented in Table 7. Bulls were more likely to be seropositive postbreeding (46\%) relative to prebreeding $(9 \%$; odds ratio adjusted for herd $2.3 ; 95 \%$ CI 1.5 to $3.1 ; P<0.001$; joint $P$ for interaction terms with herd 0.484 ). In total, $44 \%$ of the 108 bulls that were seronegative prebreeding seroconverted by their postbreeding sampling. Risk of seroconversion varied by herd $(P=0.054)$ with lowest risk in herd 1 and highest risk in herd 4 (odds ratio relative to herd $14.9 ; 95 \%$ CI 1.5 to $16.0 ; P=0.009$; Table 7 ). Mean ODC\% was 2.4 times higher (adjusted for herd; $95 \%$ CI 1.8 to $3.2 ; P<0.001$ ) postbreeding (44.1) relative to prebreeding (19.1); proportional increases in means varied by herd from 1.7 (herd 1) to 3.2 (herd 4); the joint $P$-value for the interaction terms between sample time (i.e., pre- and postbreeding) and herd was 0.040.

\section{DISCUSSION}

The colonization of 4 bulls with $M$. bovis following introduction into 3 different herds with a history of $M$. bovis disease illustrates the potential for bulls to serve as carriers for transmission of mycoplasma within and between herds. Despite low apparent prevalences of $M$. bovis in semen and preputial samples, widespread seroconversion of bulls to $M$. bovis from all 4 herds following introduction to the infected herds indicates a high incidence of exposure. Although not evaluated in this study, it is possible that bulls were colonized and shed mycoplasma from other mucosal sites. Given that we only evaluated semen and preputial swabs at a single postbreeding time point and $M$. bovis can be shed intermittently from other mucosal sites, $M$. bovis shedding in semen could be considerably higher than we have reported from bulls that have been introduced into an infected herd. Based on these results, biosecurity programs aimed at preventing the introduction of mycoplasma should ascertain the vendor's herd history with respect to disease caused by Mycoplasma spp., $M$. bovis in particular. Further, any mycoplasma disease outbreak control program should consider the potential role of bulls in transmission within a herd.

Mycoplasma bovigenitalium was the most prevalent Mycoplasma spp. isolated from the study bulls. These results are consistent with findings from Canada and the United Kingdom (Onoviran et al., 1975; Fish et al., 1985; Ball, 1990). The increase in prevalence of M. bovigenitalium from pre- to postbreeding is not surprising considering $M$. bovigenitalium also inhabits the genital tract of cows (Langford, 1975b). Mycoplasma bovigenitalium was involved in the first reported cases of mycoplasma mastitis in the United Kingdom and United States (Stuart et al., 1963; Jasper, 1977); however, in subsequent work, Stuart et al. (1963) was unable to experimentally induce mastitis using a $M$. bovigenitalium strain originally isolated from the genital tract of a cow, suggesting that pathogenicity for causing mastitis may vary between strains as documented for $M$. bovis (Punyapornwithaya et al., 2010). Mycoplasma bovigenitalium has not been reported to be associated with clinical disease outbreaks in Australian dairy herds, although it has been reported to be a cause of mastitis in dairy herds in the United States (González and Wilson, 2003) and the United Kingdom (Counter, 1978). No significant association was observed between $M$. bovigenitalium and abnormal seminal vesicular glands or poor semen quality in this study, which is consistent with findings from several other studies (Blom and Erno, 1967; Langford, 1975a; Onoviran et al., 1975) and further highlighted by Doig (1981) who reported no substantial disease or suppression of fertility in bulls that have had $M$. bovigenitalium cultured from their prepuce or semen. Previous attempts to isolate Mycoplasma spp. from bulls with seminal vesiculitis in Australia were unsuccessful (Bagshaw and Ladds, 1974). Although our study has identified a high prevalence 
of $M$. bovigenitalium in bulls in herds experiencing $M$. bovis outbreaks, no evidence was found to suggest it was a cause of disease in those herds. Isolation of $M$. bovigenitalium from $28 \%$ of the virgin bulls' prebreeding semen demonstrates that bulls do not need to have had contact with females to become colonized with this particular Mycoplasma species. These bulls were managed on a single farm in mixed groups with nonvirgin bulls, so it is possible that transmission occurred during homosexual activity or other physical contact.

Acholeplasma laidlawii was the second most prevalent Mollicutes isolated from the study bulls. In the 1970s, 2 mastitis outbreaks in Germany were attributed to $A$. laidlawii (Erfle and Brunner, 1977; Wehnert et al., 1977) and one mastitis outbreak in the United Kingdom was attributed to a rare mixed infection of A. laidlawii and M. bovigenitalium (Counter, 1978). However, Brownlie et al. (1976) were unable to experimentally induce mastitis with 4 different strains of A. laidlawii, suggesting it is relatively avirulent. This is consistent with more current thinking where A. laidlawii is considered to be a nonpathogenic contaminant from the environment or normal flora of the teat skin (González and Wilson, 2003). No reports have been made of A. laidlawii causing mastitis in Australia.

Interestingly, $M$. canadense was isolated from one bull postbreeding. Mycoplasma canadense had not been identified as a cause of any of the mycoplasma-related clinical disease in any of the herds in the current study. However, this organism has also been isolated from bulls in Denmark and Ireland (Friis and Blom, 1983; Ball, 1990) and has been associated with mycoplasma mastitis outbreaks involving other mycoplasmas including M. californicum (Mackie et al., 2000) and M. bovis in the United States and United Kingdom (Jasper, 1977; Gourlay et al., 1978).

Mycoplasma sp. Zaradi2 (also known as Mycoplasma preputii) was isolated from the prepuce of 2 bulls postbreeding. To our knowledge, no studies are available to suggest this species is of clinical significance, and it is most likely not an important pathogen but could possibly be present as part of the normal flora.

The variable clinical importance of different Mycoplasma spp. and the isolation of 5 different Mollicutes from these bulls demonstrates the importance for speciating culture-positive isolates to aid in determining their clinical significance. Most species belonging to the Acholeplasma and Mycoplasma genera have similar gross morphology of colonies on culture media. Therefore, the absence of speciating enables the potential for false-positive mycoplasma culture results.

Overall, no evidence suggested that the presence of $M$. bovis, M. bovigenitalium, or A. laidlawii in semen had significant effects on the selected semen quality attributes (percentage of sperm that were normal, semen mass activity, and semen progressive motility). This contrasts with findings of time- and dose-dependent depression in sperm motility by Panangala et al. (1981) after in vitro addition of $M$. bovigenitalium to bull semen. Jurmanova and Sterbova (1977) also demonstrated a correlation between reduced sperm motility and mycoplasma-positive semen samples (with a majority identified as $M$. bovigenitalium). The azospermic sample from the bull where $M$. bovis was isolated was likely to be a result of erroneous semen handling technique because this bull received a semen mass activity of 2 and semen progressive motility score of 30 to $50 \%$ crush side, indicating sperm must have been present in the original fresh semen sample. A greater number of $M$. bovis-infected bulls would need to be examined to better appreciate the significance of the penile lesions observed postbreeding. The leukocyte analysis showed no evidence of a significant inflammatory response to the presence of the Mollicutes in the semen. Several studies propose characteristics of $M$. bovis as mechanisms by which the pathogen evades the immune system such as possession of variable membrane surface proteins, secretory peptides, enzymatic signaling, and intracellular invasion (van der Merwe et al., 2010; Bürki et al., 2015). This may partly explain why semen quality is not affected by their presence. Similarly, this finding supports the notion that semen samples are most likely contaminated with these species from colonization of the prepuce (Fish et al., 1985) as opposed to infecting the testicles or accessory sex glands.

Comparison of semen PCR results at pre- and postbreeding demonstrated colonization of some bulls with 2 different members of the Mollicutes class. Other studies have isolated 2 different Mycoplasma spp. from the same milk (Justice-Allen et al., 2011; Boonyayatra et al., 2012), semen, or swab sample (Parker et al., 2017b). Mixed infections may be more common in bulls than our results indicate as our sub-selection of a small number of colonies from culture-positive samples for PCR typing may have limited our ability to identify mixed Mollicutes populations from individual semen or preputial swab samples.

Several of the bulls with a Mycoplasma spp. isolated prebreeding had no growth postbreeding. This may have been due to intermittent shedding or imperfect sensitivity of our detection method. Assuming bulls may remain carriers for long periods, this demonstrates the potential limitation of a single diagnostic sample in detecting carrier bulls. This limitation has previously been recognized by Ball et al. (1987) who recommended 3 or more samplings to determine whether a bull is free 
of infection. Accordingly, even if bulls from herds with histories of mycoplasma infection were sampled multiple times with negative results, the probability of at least one introduced bull being infected may be unacceptably high given the potential serious consequences of introduction of $M$. bovis to a naïve herd. Therefore, avoiding introduction of bulls from herds with a history of mycoplasma disease would be the safest option. Limited literature is available regarding the longevity of mycoplasma infection in bulls. Ball (1990) found only 1 out of 20 infected bulls to be free of mycoplasma in its last 6 out of 9 preputial washes over a 15-mo period.

Ball et al. (1987) reported higher sensitivity for mycoplasma detection from preputial sheath washings compared with fresh semen. In the current study, preputial swabs rather than sheath washings were collected postbreeding. The use of preputial swabs in addition to culture and PCR of fresh semen slightly increased the percentage of bulls where $M$. bovigenitalium and A. laidlawii were detected. Mycoplasma sp. Zaradi2 would not have been detected in 2 bulls if preputial swabs were not collected. Thus, our results show that analysis of a preputial swab in addition to fresh semen slightly increases the sensitivity of detection for some Mollicutes, although it did not increase detection of $M$. bovis. Larger numbers of $M$. bovis-infected bulls would be required to assess if preputial swabs increase detection. In practice, minimal extra effort and expense is required to collect and analyze a preputial swab, so it could therefore be considered an appropriate addition to semen culture to try and maximize sensitivity of detection. Further studies are also required to compare the sensitivity of mycoplasma detection between preputial swabs and sheath washings to identify whether preputial swabs are an appropriate alternative to sheath washings.

Collectively, seroprevalence to $M$. bovis in bulls increased 5 -fold from pre- to postbreeding samplings 55 to $57 \mathrm{~d}$ later and after short bull breeding periods of 12 to $17 \mathrm{~d}$ where bulls ran with the lactating herds. Some evidence indicated that incidence of exposure in bulls was associated with clinical disease frequency in the lactating cows during the bull breeding periods. Herd 4 experienced the highest incidence of bulls seroconverting between pre- and postbreeding. Mean ODC\% also increased the most for this herd and was the highest mean postbreeding. This herd also had substantial numbers of clinical $M$. bovis cases diagnosed during the bull breeding period, as did herd 2. Seroconversion incidence in herd 2 was intermediate. Bulls from herds 1 and 3 experienced lower incidences of seroconversion and smaller increases in mean ODC between pre- and postbreeding, and no M. bovis clinical cases were iden- tified in these herds during the bull breeding period. However, some bulls did seroconvert in these herds, even though there was no evidence of current clinical disease in the cows, potentially because the bulls were exposed to subclinical shedding cows in the lactating herds or to other bulls in the herd that were contagious. Furthermore, these changes in seroprevalence occurred without any clinical disease identified in the bulls.

The herds' prebreeding cow seroprevalences were likely to have been a function of time since the beginning of the outbreak. However, the rate of transmission of infectious agents through a herd is probably influenced by host, pathogen, and environment interactions, including farm management. Longitudinal serological studies are indicated to assess the dynamics of $M$. bovis infection and in particular, the patterns and longevity of $M$. bovis antibody persistence postinfection.

The fact that 2 out of the 4 bulls infected with $M$. bovis were seronegative postbreeding and a $3 \mathrm{rd}$ bull was only marginally positive (by $0.1 \%$ ) demonstrates that a single serological test using the Bio-X $M$. bovis ELISA has imperfect diagnostic sensitivity for detecting infection status and therefore transmission risk of individual animals. This finding is supported by Wawegama et al. (2016) who reported a diagnostic sensitivity of only $37 \%$ for the Bio-X ELISA in dairy calves experimentally infected with $M$. bovis. Alternatively, Wawegama et al. (2014) detected M. bovis-specific IgG antibodies 3 wk postinfection, so if these bulls became infected at the end of the bull breeding period, enough time may not have passed before postbreeding sampling (12 or 13 $\mathrm{d}$ after the last day of the breeding period) to enable seroconversion to be detected.

\section{CONCLUSIONS}

Bulls can become colonized with $M$. bovis when used in herds with a history of $M$. bovis clinical disease and can shed the organism in semen. Infected bulls could therefore increase the risk of entry of $M$. bovis into other herds or, potentially, transmission within a herd. Seroconversion was observed in a high proportion of the bulls in all of the herds sampled, indicating that subclinical $M$. bovis infections are common in clinically affected herds. This also indicates that the transmission can occur through pathways not associated with milking, a recognized risk factor for transmission between cows. Those developing biosecurity protocols and control measures should consider the role of bulls as a risk factor for transmission. We found no evidence that M. bovigenitalium, M. bovis, and A. laidlawii have large adverse effects on semen quality. 


\section{ACKNOWLEDGMENTS}

This work was financially supported by Dairy Australia (Southbank, VIC, Australia). Technical assistance provided by Ann-Marie House and Karen Mathews from the Sydney School of Veterinary Science, Faculty of Science, The University of Sydney (Australia), was greatly appreciated. Many thanks to Simon De Graaf from the School of Life and Environmental Sciences, Faculty of Science, The University of Sydney (Australia) for coordinating the semen morphology analysis. This work could not have been possible without the incredible co-operation of all of the herd managers and staff.

\section{REFERENCES}

Abramson, J. H. 2011. WINPEPI updated: Computer programs for epidemiologists, and their teaching potential. Epidemiol. Perspect. Innov. 8:1.10.1186/1742-5573-8-1.

al-Aubaidi, J. M., K. McEntee, D. H. Lein, and S. J. Roberts. 1972. Bovine seminal vesiculitis and epididymitis caused by Mycoplasma bovigenitalium. Cornell Vet. 62:581-586.

Arede, M., P. K. Nielsen, S. S. U. Ahmed, T. Halasa, L. R. Nielsen, and N. Toft. 2016. A space-time analysis of Mycoplasma bovis: Bulk tank milk antibody screening results from all Danish dairy herds in 2013-2014. Acta Vet. Scand. 58:16. https://doi.org/10 .1186/s13028-016-0198-3.

Bagshaw, P. A., and P. W. Ladds. 1974. A study of the accessory sex glands of bulls in abattoirs in Northern Australia. Aust. Vet. J. 50:489-495.

Ball, H. J. 1990. Use of bovine sheath washings for screening for mycoplasmas. Vet. Rec. 127:16-17.

Ball, H. J., E. F. Logan, and W. Orr. 1987. Isolation of mycoplasmas from bovine semen in Northern Ireland. Vet. Rec. 121:322-324.

Beggs, D., J. Bertram, P. Chenworth, K. Entwistle, G. Fordyce, H. Johnston, P. Johnston, M. McGowan, G. Niethe, S. Norman, and V. Perry. 2013. Veterinary Bull Breeding Soundness Evaluation. D. Beggs, ed. Australian Cattle Veterinarians-A special interest group of the Australian Veterinary Association, Eight Mile Plains, QLD, Australia.

Blom, E., and H. Erno. 1967. Mycoplasmosis: Infections of the genital organs of bulls. Acta Vet. Scand. 8:186-188.

Blom, E., N. F. Friis, and H. Erno. 1983. Mycoplasmas: Demonstration in semen and preputial washings from bulls. Acta Vet. Scand. $24: 238-240$.

Boonyayatra, S., L. K. Fox, T. E. Besser, A. Sawant, J. M. Gay, and Z. Raviv. 2012. A PCR assay and PCR-restriction fragment length polymorphism combination identifying the 3 primary Mycoplasma species causing mastitis. J. Dairy Sci. 95:196-205. https://doi.org/ 10.3168/jds.2011-4531.

Brownlie, J., C. J. Howard, and R. N. Gourlay. 1976. The pathogenicity of certain mycoplasma species in the bovine mammary gland. Res. Vet. Sci. 20:261-266.

Bürki, S., V. Gaschen, M. H. Stoffel, A. Stojiljkovic, J. Frey, K. Kuehni-Boghenbor, and P. Pilo. 2015. Invasion and persistence of Mycoplasma bovis in embryonic calf turbinate cells. Vet. Res. 46:53. https://doi.org/10.1186/s13567-015-0194-z.

Catania, S., A. Tavella, F. Gobbo, and R. A. J. Nicholas. 2014. The isolation of Mycoplasma bovigenitalium from infertile dairy cattle. pdf. Vet. Rec. Case Rep. 2:1-2.

Counter, D. E. 1978. A severe outbreak of bovine mastitis associated with Mycoplasma bovigenitalium and Acholeplasma laidlawii. Vet. Rec. 103:130-131.

Doig, P. A. 1981. Bovine genital mycoplasmosis. Can. Vet. J. 22:339343.
Erfle, V., and A. Brunner. 1977. Bovine mastitis caused by Acholeplasma laidlawii. Berl. Munch. Tierarztl. Wochenschr. 90:28-34.

Erno, H., and E. Blom. 1972. Mycoplasmosis: Experimental and spontaneous infections of the genital tract of bulls. Acta Vet. Scand. $13: 161-174$

Evans, G., and W. M. C. Maxwell. 1987. Salamon's Artificial Insemination of Sheep and Goats. Butterworths, Sydney, Australia.

Fish, N. A., S. Rosendal, and R. B. Miller. 1985. The distribution of mycoplasmas and ureaplasmas in the genital tract of normal artificial insemination bulls. Can. Vet. J. 26:13-15.

Fox, L. K. 2012. Mycoplasma mastitis. Causes, transmission, and control. Vet. Clin. North Am. Food Anim. Pract. 28:225-237. https:// doi.org/10.1016/j.cvfa.2012.03.007.

Fox, L. K., J. H. Kirk, and A. Britten. 2005. Mycoplasma mastitis: A review of transmission and control. J. Vet. Med. B Infect. Dis. Vet. Public Health 52:153-160. https://doi.org/10.1111/j.1439-0450 .2005.00845.x.

Friis, N. F., and E. Blom. 1983. Isolation of Mycoplasma canadense from bull semen. Acta Vet. Scand. 24:315-317.

González, R. N., and D. J. Wilson. 2003. Mycoplasmal mastitis in dairy herds. Vet. Clin. North Am. Food Anim. Pract. 19:199-221.

Gourlay, R. N., S. G. Wyld, N. F. S. Burke, and M. J. Edmonds. 1978. Isolation of Mycoplasma canadense from an outbreak of bovine mastitis in England. Vet. Rec. 103:74-75.

Jasper, D. 1977. Mycoplasma and mycoplasma mastitis. J. Am. Vet. Med. Assoc. 170:1167-1172.

Jurmanova, K., and J. Sterbova. 1977. Short communication: Correlation between impaired spermatozoan motility and mycoplasma findings in bull semen. Vet. Rec. 100:157-158.

Justice-Allen, A., J. Trujillo, G. Goodell, and D. Wilson. 2011. Detection of multiple Mycoplasma species in bulk tank milk samples using real-time PCR and conventional culture and comparison of test sensitivities. J. Dairy Sci. 94:3411-3419. https://doi.org/10 .3168/jds.2010-3940.

Langford, E. 1975a. Mycoplasma recovered from bovine male and female genitalia and aborted foeti. Pages 221-232 in Proceedings of the 18th Annual Meeting of the American Association of Veterinary Laboratory Diagnosticians, Portland, OR. AAVLD, Visalia, CA.

Langford, E. V. 1975b. Mycoplasma species recovered from the reproductive tracts of western Canadian cows. Can. J. Comp. Med. 39:133-138.

Mackie, D. P., D. Finlay, N. Brice, and H. J. Ball. 2000. Mixed mycoplasma mastitis outbreak in a dairy herd. Vet. Rec. 147:335-336.

Marciszewska, M., and I. Zgorniak-Nowolielska. 1987. Biological properties of mycoplasmas isolated from the semen of bulls. Pol. Arch. Weter. 27:75-87.

Maunsell, F., M. B. Brown, J. Powe, J. Ivey, M. Woolard, W. Love, and J. W. Simecka. 2012. Oral inoculation of young dairy calves with Mycoplasma bovis results in colonization of tonsils, development of otitis media and local immunity. PLoS One 7:e44523. https://doi.org/10.1371/journal.pone.0044523.

Maunsell, F. P., A. R. Woolums, D. Francoz, R. F. Rosenbusch, D. L. Step, D. J. Wilson, and E. D. Janzen. 2011. Mycoplasma bovis infections in cattle. J. Vet. Intern. Med. 25:772-783. https://doi .org/10.1111/j.1939-1676.2011.0750.x.

Onoviran, O., R. B. Truscott, N. A. Fish, C. A. V. Barker, and H. L. Ruhnke. 1975. The recovery of mycoplasmas from the genital tracts of bulls in artificial breeding units in Ontario. Can. J. Comp. Med. 39:474-475.

Panangala, V. S., J. A. Winter, A. Wijesinha, and R. H. Foote. 1981. Decreased motility of bull spermatozoa caused by Mycoplasma bovigenitalium. Am. J. Vet. Res. 42:2090-2093.

Parker, A. M., J. K. House, M. S. Hazelton, K. L. Bosward, J. M. Morton, and P. A. Sheehy. 2017a. Bulk tank milk antibody-ELISA as a biosecurity tool for detecting dairy herds with past exposure to Mycoplasma bovis. J. Dairy Sci. https://doi.org/10.3168/jds.2016 -12468 .

Parker, A. M., J. K. House, M. S. Hazelton, K. L. Bosward, and P. A. Sheehy. 2017b. Comparison of culture and a multiplex probe PCR for identifying Mycoplasma species in bovine milk, semen and 
swab samples. PLoS One 12:e173422. https://doi.org/10.1371/ journal.pone.0173422.

Parker, A. M., A. Shukla, J. K. House, M. S. Hazelton, K. L. Bosward, B. Kokotovic, and P. A. Sheehy. 2016. Genetic characterization of Australian Mycoplasma bovis isolates through whole genome sequencing analysis. Vet. Microbiol. 196:118-125. https://doi.org/ 10.1016/j.vetmic.2016.10.010.

Pfützner, H., and K. Sachse. 1996. Mycoplasma bovis as an agent of mastitis, pneumonia, arthritis and genital disorders in cattle. Rev. Sci. Tech. 15:1477-1494.

Punyapornwithaya, V., L. K. Fox, D. D. Hancock, J. M. Gay, and J. R. Alldredge. 2010. Association between an outbreak strain causing mycoplasma bovis mastitis and its asymptomatic carriage in the herd: A case study from Idaho, USA. Prev. Vet. Med. 93:66-70. https://doi.org/10.1016/j.prevetmed.2009.08.008.

Ruhnke, H. L. 1994. Mycoplasmas associated with bovine genital tract infections. Pages 56-61 in Mycoplasmosis in Animals: Laboratory Diagnosis. H. W. Whitford, R. F. Rosenbusch, and L. H. Lauerman, ed. Iowa State University Press, Ames.

Stuart, P., I. Davidson, G. Slavin, F. A. Edgson, and D. Howell. 1963. Bovine mastitis caused by mycoplasma. Vet. Rec. 75:59-64.

Tourtellotte,, M. E. 1976. Infertility of cattle caused by mycoplasmas. Health Lab. Sci. 13:152-158.

Ungureanu, C., C. Grigore, F. Ionita-Ionescu, and L. Constantinescu. 1986. Frequency of Mycoplasmae in the semen of reproduction bulls. Arch. Exp. Veterinarmed. 40:82-87.
Untergasser, A., I. Cutcutache, T. Koressaar, J. Ye, B. C. Faircloth M. Remm, and S. G. Rozen. 2012. Primer3-New capabilities and interfaces. Nucleic Acids Res. 40:e115.

van der Merwe, J., T. Prysliak, and J. Perez-Casal. 2010. Invasion of bovine peripheral blood mononuclear cells and erythrocytes by Mycoplasma bovis. Infect. Immun. 78:4570-4578. https://doi.org/ 10.1128/IAI.00707-10.

Wawegama, N. K., G. F. Browning, A. Kanci, M. S. Marenda, and P. F. Markham. 2014. Development of a recombinant protein-based enzyme-linked immunosorbent assay for diagnosis of Mycoplasma bovis infection in cattle. Clin. Vaccine Immunol. 21:196-202. https://doi.org/10.1128/CVI.00670-13.

Wawegama, N. K., P. F. Markham, A. Kanci, M. Schibrowski, S. Oswin, T. S. Barnes, S. M. Firestone, T. J. Mahony, and F. Browning. 2016. Evaluation of an IgG enzyme-linked immunosorbent assay as a serological assay for detection of Mycoplasma bovis infection in feedlot cattle. J. Clin. Microbiol. 54:1269-1275. https://doi .org/10.1128/JCM.02492-15.

Wehnert, C., G. Teichmann, H. Hauke, D. Schimmel, and C. Lantzsch. 1977. Course of Mycoplasma infection of the udder. Monatsh. Veterinarmed. 32:55-59. 